\title{
A formação do técnico de enfermagem fundamentada nas diretrizes da reforma psiquiátrica e nos quatro pilares da educação
}

\author{
Livia Maria Dodds \\ Instituto Federal da Bahia - IFBA \\ (livia.dodds@ifba.edu.br) \\ Laís Santana Santos Pereira Lira \\ Instituto Federal da Bahia - IFBA \\ (lais.lira@ifba.edu.br)
}

\begin{abstract}
Resumo: Este trabalho tem por objetivo relatar a experiência acadêmica com formandos do curso Técnico em Enfermagem do Instituto Federal da Bahia (IFBA), campus Eunápolis, norteada pelas diretrizes da Reforma Psiquiátrica e pelos quatro pilares da educação: aprender a conhecer, aprender a fazer, aprender a conviver, aprender a ser. A proposta foi desenvolvida durante o período letivo de realização do módulo Assistência em Saúde Mental, composto pela área da Enfermagem e da Psicologia. Neste período, o processo formativo se deu a partir da relação teórico-prática nas atividades pedagógicas de ensino/aprendizagem: atividades realizadas em sala de aula, estágio curricular supervisionado, atividades avaliativas interdisciplinares, projeto interdisciplinar e visita técnica. A partir dessa experiência, conclui-se que a relação entre o docente e o discente deve possibilitar a construção de um novo saber-fazer em Saúde Mental, capaz de superar o caráter puramente tecnicista da formação em Enfermagem Psiquiátrica. Neste sentido, as práticas pedagógicas devem ser capazes de superar o caráter punitivo, vigilante, controlador e disciplinador que acompanhou as atividades da profissão ao longo da história da psiquiatria tradicional.
\end{abstract}

Palavras-chave: Enfermagem; Reforma Psiquiátrica; Processo ensino/aprendizagem.

The training of the nursing technician based in the guidelines of the psychiatric reform and in the four pillars of education

Abstract: This work aims to report an academic experience with students of the Nursing Technical Course of the Instituto Federal da Bahia (IFBA), Eunápolis campus, conducted by the guidelines of the Psychiatric Reform and the Four Pillars of Education: learning to know, learning to do; learning to live; learning to be. The proposal was developed during the academic period of the implementation of the Mental Health Assistance module, composed by Nursing and Psychology areas. In that period, the formative process was based on the theoretical-practical relationship in teaching/learning activities: classroom activities, supervised curricular practice, interdisciplinary evaluative activities, interdisciplinary project and technical visits. Based on that experience, it is concluded that the relationship between the teacher and the student should enable the construction of a new know-how in Mental Health, which is able to overcome the simply technical character of the training in Psychiatric Nursing. Therefore, pedagogical practices must be able to overcome the punitive, vigilant, controlling and disciplinary character that has accompanied the activities of the profession throughout the history of traditional psychiatry.

Keywords: nursing; psychiatric reform; teaching/learning process. 


\section{INTRODUÇÃO}

A reforma psiquiátrica, no Brasil, inicia com o projeto de lei (PL-3657/1989) que foi fortemente influenciada pela Lei 180/1978 de Franco Basaglia, na Itália, tendo como uma das principais vertentes a desinstitucionalização. Apresenta como proposta um novo modelo de assistência a partir da extinção dos manicômios e a quebra dos paradigmas da psiquiatria tradicional. Durante o modelo clássico da psiquiatria, as habilidades da área da enfermagem só eram consideradas necessárias quando se estava lidando com os insanos (KYES, 1986), uma vez que os hospícios não exigiam profissionais com qualificação para o exercício deste trabalho. A assistência estava longe de ser uma prioridade, pois estes espaços, até então, eram vistos como lugares de padecimento, e para onde as enfermeiras problemáticas eram encaminhadas como forma de punição por mau comportamento (BELMONTE, 1996).

Neste contexto, a vigilância, o controle, a organização, a imposição pela força, a contenção, a fiscalização e a disciplina se tornam tarefas prioritárias deste modelo de enfermagem psiquiátrica e passam a caracterizar esta profissão, no sentido de evitar a ociosidade dos sujeitos considerados loucos (BELMONTE, 1996). Assim, de forma muito incipiente e ainda pouco valorizada nos currículos que nasce a reforma psiquiátrica.

A partir da instalação da Reforma Psiquiátrica, a proposta do trabalho do profissional da Enfermagem na atenção ao paciente psiquiátrico passa a ter como objetivo promover a prevenção do transtorno mental, bem como, realizar estratégias de reabilitação a partir de uma visão biopsicossocial, levando em conta a subjetividade do ser humano, os relacionamentos interpessoais, a promoção do autocuidado, a responsabilização do sujeito pela sua saúde, o fortalecimento do vínculo familiar e a reinserção social (LACCHINI; RIBEIRO; SOCCOL; TERRA; SILVA, 2011).

Frente a essas mudanças no exercício da atividade de Enfermagem observase a necessidade da formação de profissionais capacitados e humanizados, prontos a prestar assistência junto ao sujeito com transtorno mental a partir de ações terapêuticas e de reabilitação, pautadas na ideia de promoção à saúde, qualidade de vida e com o objetivo de incentivar/ampliar a autonomia dos sujeitos na gestão da vida e para o resgate da cidadania. 
Neste sentido, este artigo tem como objetivo relatar a experiência acadêmica com formandos do curso Técnico em Enfermagem do Instituto Federal da Bahia (IFBA), campus Eunápolis, norteada pelas diretrizes da Reforma Psiquiátrica e pelos Quatro Pilares para a Educação do Século XXI (DELORS, 2003): "Aprender a conhecer", "Aprender a fazer", "Aprender a ser" e "Aprender a conviver".

\section{REFERENCIAL TEÓRICO}

Buscando contextualizar o relato de experiência, primeiramente se abordará sobre a "Reforma Psiquiátrica" (BELMONTE, 1996; TENÓRIO, 2002; BRASIL, 2005; FERNANDES, SADIGURSKY, SILVA, AMORIM, TEIXEIRA, ARAÚJO, 2009; BRASIL, 2015) e na sequência, sobre "Os Quatro Pilares da Educação" (DELORS, 2003).

\subsection{Reforma psiquiátrica}

Contemporâneo ao movimento sanitário, o início do processo da Reforma Psiquiátrica, aconteceu nos anos 70 na Itália, tendo como marca o "reclame da cidadania do louco" (TENÓRIO, 2002, p. 27). Parte de uma formulação crítica e prática com o objetivo de questionar o modelo clássico do paradigma psiquiátrico e condenar a normatização e o controle das instituições psiquiátricas. Ainda segundo o mesmo autor, torna-se possível localizar a cidadania como valor fundante e organizador das práticas de cuidado dirigidas aos "loucos". A Reforma Psiquiátrica não foi um momento histórico, porém
constitui-se em um processo político e social complexo, composto de
atores, instituições e forças de diferentes origens, e que incide em
territórios diversos (...) Compreendida como um conjunto de
transformações de práticas, saberes, valores culturais e sociais, é no
cotidiano da vida das instituições, dos serviços e das relações
interpessoais que o processo da Reforma Psiquiátrica avança,
marcado por impasses, tensões, conflitos e desafios (BRASIL, 2005,
p. 6)

A Reforma Psiquiátrica no Brasil, influenciada pela experiência da Psiquiatria Democrática Italiana (BASAGLIA, 1981, p. 504), defende o paradigma da 
desinstitucionalização em saúde mental, que considerava o manicômio tradicional antiterapêutico, devendo ser substituído por outros serviços de base territorial (BRASIL, 2005). Desinstitucionalizar é mais que desospitalizar, é uma crítica a todo tipo de abandono e desassistência, repensando a loucura enquanto um processo singular, social, biológico, cultural e histórico. Além disso, este processo busca resgatar a cidadania dos sujeitos com transtornos mentais de forma interdisciplinar (BRASIL, 2015).

A partir da reordenação do modelo de atenção médico-psiquiátrica para serviços de base territorial e comunitária fundamentados no paradigma da Atenção Psicossocial, pode-se romper com saberes e práticas suplantadas e, consequentemente, fortalecer práticas antimanicomiais e diferenciadas na atenção em saúde mental. Esse paradigma, amparado na Reforma Psiquiátrica, traz como diretrizes a construção de espaços de atenção ao sofrimento psíquico, a reabilitação psicossocial, o acolhimento, a afirmação da cidadania, a produção de novas subjetividades, o estímulo à autonomia desses sujeitos, desenvolvendo, assim, novas práticas e novas formas de pensar e agir, reinventando os modos de lidar com a loucura (FERNANDES; SADIGURSKY; SILVA; AMORIM; TEIXEIRA; ARAÚJO, 2009).

\subsection{Os quatro pilares da educação para o século XXI}

Um dos desafios do processo ensino/aprendizagem é a de se encontrar maneiras para conseguir orientar os educandos de maneira a propiciar uma formação integrada. Para isso, DELORS (2003) acredita que a educação do século XXI tem que estar alicerçada em Quatro Pilares, que este autor considera como sendo as bases para a educação, uma vez que verdadeiramente liberta da ignorância, estimula o papel do cidadão e o objetivo de viver, sendo estes: "Aprender a conhecer", "Aprender a fazer", "Aprender a conviver" e "Aprender a ser".

"Aprender a conhecer" se refere ao descobrimento e o conhecimento, porém buscando estimular no educando a compreensão do mundo que nos cerca, sendo esta considerada uma aprendizagem que deve ocorrer durante todas as fases da vida do sujeito. Já "Aprender a fazer", consiste na formação profissional, porém destaca que na educação da atualidade também é preciso agregar as habilidades 
interpessoais e de comunicação buscando despertar o pensamento crítico frente às diversas situações de vida.

"Aprender a conviver" diz respeito à aceitação da diversidade através do incentivo da realização de trabalhos em grupo, da administração de conflitos, da adoção de comportamentos que valorizem a coletividade em detrimento da individualidade, bem como ações que fomentem a transformação social a partir de uma formação que combine habilidade técnica, habilidade humana e ética. E o quarto pilar se refere a "Aprender a ser", que deve auxiliar no desenvolvimento total da pessoa com aprimoramento da área intelectual, responsabilidade pessoal, responsabilidade social, sensibilidade, sentido estético e espiritualidade.

Embora haja uma tentativa didática de descrever os pilares separadamente, essas quatro estruturas precisam operar de modo interligado para possibilitarem uma formação integral do sujeito tanto no plano cognitivo como no prático.

\section{PROCESSO DE FORMAÇÃO: RELAÇÃO TEÓRICO-PRÁTICA}

O processo da educação para a formação profissional acontece através da relação do docente com o discente, permeada pelo acesso a uma diversidade de conhecimentos teóricos, bem como pela prática pedagógica que tem a função de oferecer experiência e que poderá se assentar nos quatro pilares da educação.

De acordo com o atual Projeto Pedagógico do Curso Técnico em Enfermagem do IFBA, campus Eunápolis, a formação deverá proporcionar ao discente o desenvolvimento das competências e habilidades necessárias para o desempenho de atividades de Enfermagem, como membro de equipe multiprofissional da área da saúde; contribuir para a qualidade da assistência de enfermagem no sistema de atenção à saúde do Município de Eunápolis e região; formar profissionais, a fim de que os mesmos desenvolvam competências cognitivas, psicomotoras e afetivas para executar ações de Enfermagem, sob supervisão do Enfermeiro, fundamentadas nos conhecimentos técnico científicos, éticos e educacionais, a fim de contribuir para a qualidade do Cuidar em Enfermagem.

Observa-se nessas concepções a importância de que os processos de ensino e aprendizagem ocorram de forma integrada entre a teoria e prática visando proporcionar uma formação globalizada do Técnico em Enfermagem. Para tanto, a 
formação requer do profissional não só competências técnicas isoladas, mas articulação com as competências ética e política de modo a contribuir com um sistema de saúde que está em contínua implementação. Busca-se então a formação de um sujeito que seja um agente de mudanças.

Segundon Lippitt, Watson e Westley (1958), o agente de mudança é o sujeito convidado por um sistema a contribuir, através de ações planejadas, para a ocorrência de mudanças e melhorias desse sistema. Acrescenta ainda que, para a formação deste sujeito enquanto agente de mudança, é necessária uma experiência educacional com uma abordagem integrada, a qual define como sendo a associação de fundamentação teórica e prática.

Buscando oportunizar essa educação integrada, este trabalho trata do relato de experiência acadêmica do módulo Saúde Mental, constituído pelas áreas da Enfermagem e da Psicologia, realizada com vinte estudantes do quarto e último módulo do curso de Técnico de Enfermagem do IFBA (Instituto Federal de Educação, Ciência e Tecnologia da Bahia), Campus Eunápolis, durante o primeiro semestre de 2017.

Esse módulo tem como competência chave promover, manter e recuperar a integridade mental, emocional e o equilíbrio na relação do cliente/paciente com o meio em que vive e aponta como objetivo norteador desenvolver uma análise da inserção do Técnico em Enfermagem no mundo do trabalho, identificando entraves e avanços em sua atuação, estimulando assim uma visão crítica do seu processo de trabalho.

As atividades se desenvolveram em diversos espaços com diferentes práticas pedagógicas, tais como: atividades realizadas em sala de aula, estágio curricular supervisionado, organização de dois eventos, desenvolvimento de projeto interdisciplinar e realização de visita técnica.

\section{METODOLOGIA}

Dentre as habilidades teóricas e práticas a serem desenvolvidas no módulo de Saúde Mental, o discente deve aprender a: prestar assistência de Enfermagem em quadros agudos e crônicos de transtorno mental, prestar cuidados de Enfermagem direcionados às diversas formas de tratamento dos transtornos mentais, 
empregar medidas de prevenção, administrar medicamentos psicotrópicos, intervir em situações de emergência, atuar na equipe multiprofissional, referenciar usuários e familiares na atenção em Saúde Mental, aplicar conhecimentos da Psicologia, desenvolver uma visão holística do sujeito com transtorno mental e estabelecer comunicação eficiente com sujeitos e familiares.

Para alcançar essas habilidades, buscou-se desenvolver atividades integradas e interdisciplinares entre a Enfermagem e a Psicologia. Em sala de aula, o desafio foi superar a abordagem tradicional que tem como fundamento a transmissão e a retenção da informação, na qual o professor ensina e o aluno aprende. As práticas de ensino foram realizadas a partir de experiências dialógicas, o que remete à dialogicidade de Paulo Freire e sua capacidade de transformar a prática pedagógica, na qual o docente e o discente participam de forma ativa do processo ensino/aprendizagem.

Ao fundar-se no amor, na humildade, na fé nos homens, o diálogo se faz uma relação horizontal, em que a confiança de um polo no outro é consequência óbvia. Seria uma contradição se, amoroso, humilde e cheio de fé, o diálogo não provocasse este clima de confiança entre sujeitos. (FREIRE, 2007, p. 94)

Os momentos em sala de aula realizaram-se a partir de discussões em grupo, nas quais os discentes e as docentes puderam dialogar de forma reflexiva e construtiva no processo ensino/aprendizagem. Para isso, foram utilizadas leitura de textos, filmes e documentários relevantes na Saúde Mental, técnicas de atividades grupais, construção de painel ilustrativo, encenações improvisadas, aulas expositivas e dialogadas na qual os discentes puderam colocar as suas angústias e experienciar o cuidado no próprio espaço acadêmico.

Todas as metodologias utilizadas foram disparadoras da construção do saber/fazer em Saúde Mental, tornando o discente ativo no seu processo de formação. Neste sentido, o professor deixa de ser transmissor de conhecimento e passa a possibilitar a produção e a construção, a partir da compreensão de que todos são sujeitos, o que supera o sentido vertical e institui o sentido horizontal do processo ensino/aprendizagem (SAVIANI, 2003).

"Aprender a conhecer" implica que cada um compreenda, conheça e descubra o mundo que o rodeia de forma prazerosa, para desenvolver suas capacidades profissionais. Ao ofertar diversas metodologias de ensino em sala de 
aula de forma mais ativa e vivencial, a relação docente/discente proporciona o aumento de saberes, a partir da melhor compreensão do ambiente sob diversos aspectos, despertando a curiosidade intelectual, o sentido crítico, o entendimento do real e a aquisição da autonomia na capacidade de discernir (DELORS, 2003).

O processo de trabalho do Técnico em Enfermagem na saúde mental, muitas vezes, tem como objeto o comportamento patológico do sujeito, com foco no trabalho da remissão da sintomatologia. No entanto a maioria dos técnicos não teve formação suficiente no que se refere a atuação humanizada no trabalho na saúde mental, tanto nas questões práticas como teóricas, o que revela a predominância do modelo biológico nas práticas do profissional de nível médio (ZERBETTO; PEREIRA, 2005).

Para isso, é importante que o professor desenvolva suas abordagens pedagógicas fundamentadas numa ação reflexiva e consciente do saber-fazer em saúde mental num contínuo processo de construir/desconstruir capaz de superar uma formação tecnicista e de relações de poder, para um modelo baseado em ações terapêuticas integrais, acolhedoras e, verdadeiramente, capazes de efetivar a reinserção social.

\subsection{Estágio curricular supervisionado}

O Estágio Curricular Supervisionado faz parte do Projeto Pedagógico do Curso, que além de integrar o itinerário formativo do discente, promove o aprendizado de competências próprias da atividade profissional, objetivando o desenvolvimento do estudante para a vida cidadã e para o trabalho.

Os estágios foram realizados no Centro de Atenção Psicossocial para infância e adolescência (CAPS ia), no CAPS ad (para usuários de álcool e outras drogas) e no CAPS II (para pessoas com transtornos mentais severos e persistentes) do município de Eunápolis/BA. O CAPS é um serviço de saúde substitutivo ao hospital psiquiátrico, aberto, de base comunitária, formado por equipes multiprofissionais que devem atuar numa perspectiva interdisciplinar. É um local de referência para o tratamento de pessoas com transtornos mentais graves, severos e persistentes que justifiquem a sua permanência num dispositivo de cuidado intensivo, comunitário, personalizado e que promova a vida através de práticas intersetoriais que envolvam a educação, o trabalho, o esporte, a cultura e o lazer, além de outras ações, como 
atendimentos individuais, atividades grupais, promoção de espaços de convivência, oficinas, tratamento medicamentoso, dentre outros (BRASIL, 2004).

No primeiro contato com o CAPS, os discentes passam um período dialogando com os usuários a fim de partilharem histórias, sonhos, projetos, preferências, atividades que realizam e aspectos sobre as relações familiares e sociais. Importante salientar que esses encontros são realizados sem discussão prévia sobre os diagnósticos. Além disso, são os próprios usuários que apresentam a estrutura e toda a equipe do serviço. Esse primeiro contato é importante para o processo de desconstrução dos estigmas e preconceitos relacionados à loucura, já que os estudantes chegam no campo de estágio ainda assustados diante de sujeitos com contextos até então desconhecidos para a maioria deles.

Embora existam muitos avanços no campo da Saúde Mental, a estigmatização da loucura prevaleceu ao longo dos tempos, o que acarretou num processo de exclusão social desses sujeitos, fazendo-os viverem à margem da sociedade (MACIEL; MACIEL; BARROS; SÁ; CAMINO, 2008). Nesse contexto, é importante que o professor possibilite a aproximação dos discentes com os usuários desde o primeiro dia de estágio, dando autonomia e responsabilidade à pessoa com transtorno mental, no intuito de possibilitar vê-lo como um sujeito e não como um doente mental, configurando-se em um processo de aprendizagem que enfatize ao estudante o pilar da educação volta ao de "Aprender a conviver".

Em um estudo realizado com objetivo de analisar o processo de comunicação terapêutica desenvolvida pela enfermagem, percebeu-se que o relacionamento interpessoal e a comunicação não foram efetivos como deveriam (PONTES; LEITÃO; RAMOS, 2008). Neste sentido, é preciso trabalhar e desenvolver estratégias para a efetivação da comunicação terapêutica entre a enfermagem e os usuários dos diversos serviços. Assim, através da comunicação, as pessoas expressam o que são, se revelam, se relacionam, se emocionam e podem construir e reconstruir os projetos terapêuticos de acordo com suas necessidades. É nesse contexto que o papel da Enfermagem não se restringe ao uso de técnicas, mas em ações de cuidado mais resolutivas.

A partir das diretrizes da Reforma Psiquiátrica, as organizações das práticas de saúde e das relações terapêuticas na produção do cuidado fundamentadas em tecnologias leves ou relacionais, possibilita de forma criativa, a manifestação da subjetividade do outro, a partir do acolhimento, da escuta, do vínculo, da autonomia 
e da responsabilização na organização da assistência em saúde, a fim de alcançar a integralidade e a humanização do cuidado (JORGE; PINTO; QUINDERÉ; PINTO; SOUSA; CAVALCANTE, 2011).

A Reforma Psiquiátrica coloca em pauta a questão da ética, da cidadania dos portadores de sofrimento psíquico e o processo de desinstitucionalização, apontando para novas possibilidades no campo terapêutico. Ela não se apresenta mais como uma palavra abstrata, mas faz parte do cotidiano dos serviços de saúde, que além de observar o quadro clínico, passou a conhecer a história de vida dos pacientes (MORENO; SAEKI, 1998).

Durante o período de estágio, os discentes puderam acompanhar acolhimentos iniciais realizados pelos profissionais dos serviços, bem como consultas médicas e atendimentos individuais da Enfermagem, inclusive do profissional Técnico em Enfermagem do serviço. Também participaram de atividades grupais para construção de propostas de geração de renda, oficinas de artesanato para usuários e familiares, ornamentação do serviço em período de festas juninas, ensaios de quadrilha, visita domiciliar, contato com prontuários, livros e sistemas computadorizados utilizados pelos serviços e administração de medicamentos psicotrópicos.

Embora o "Aprender a conhecer" e o "Aprender a fazer" sejam pilares educativos indissociáveis, a segunda aprendizagem está estreitamente ligada à capacidade de pôr os conhecimentos em prática, num processo de adaptação entre a educação e o trabalho futuro. Nesse contexto, a simples execução de trabalho prescritos é substituída pela organização de coletivos de trabalho ou grupos de projeto, formando o discente para a aptidão ao trabalho em equipe e para a capacidade de iniciativa.

Apesar das dificuldades de transportes, alguns discente realizaram visita domiciliar, o que é um ponto importante dentro das ações desenvolvidas no estágio, possibilitando a melhor compreensão dos processos relacionais que o sujeito vivencia no contexto familiar e social. As visitas domiciliares constituem um instrumento facilitador no cuidado ao usuário e à sua família no contexto da Reforma Psiquiátrica, pois através desse dispositivo de cuidado, os profissionais de saúde mental podem compreender melhor as relações familiares e sociais dos sujeitos, ou a ausência delas, bem como acompanhar os usuários no território, buscando envolver outros atores sociais no contexto (REINALDO; ROCHA, 2002). 
Além de acompanhar as atividades desenvolvidas pelas equipes, os estudantes foram desafiados a construírem intervenções grupais nas atividades de estágio. Nesse contexto, os discentes puderam organizar atividades grupais com os usuários dos CAPS, desenvolvendo a autonomia para a prática profissional. $\mathrm{O}$ "Aprender a fazer", neste contexto, possibilita ao discente aprender a se comunicar, a trabalhar com outros, a gerir e resolver conflitos, cultivando qualidade humanas que formações tradicionais não conseguem transmitir.

As práticas realizadas nos CAPS são caracterizadas por ocorrerem em ambiente aberto, acolhedor e inserido na cidade, no território. A proposta desses serviços muitas vezes ultrapassa a estrutura física em busca de ações intersetoriais e da construção de redes de cuidados em saúde mental (BRASIL, 2004). Neste sentido, os discentes em campo de estágio tiveram a oportunidade de acompanhar os usuários em atividades extramuros desenvolvidas pelo Núcleo de Apoio à Saúde da Família (NASF), na Academia da Saúde localizada numa praça em um bairro vizinho ao endereço do CAPS. Assim, se faz importante a utilização pelo docente dos serviços substitutivos como os CAPS, no intuito de concretizá-los como espaços de ensino-aprendizagem a partir de vivências problematizadoras possibilitando uma relação íntima entre a teoria e a prática (ZERBETTO; PEREIRA, 2005).

Durante décadas, o atendimento à pessoa com transtorno mental era ligado ao internamento psiquiátrico, longe do convívio social e familiar. Nesse contexto, é necessário que a formação do técnico em Enfermagem, como membro da equipe multiprofissional do CAPS, seja fundamentada pelas diretrizes da Reforma Psiquiátrica, a fim de superar as práticas tecnicistas que acompanham a Enfermagem há décadas. Para isto, torna-se imprescindível o desenvolvimento de competências interpessoais para atuar dentro de uma equipe multiprofissional e interdisciplinar. Acrescenta-se também o senso crítico-reflexivo e autocrítica, iniciativa, flexibilidade, senso de observação acurado, capacidade de autogestão, abstração e raciocínio lógico.

\subsection{Avaliações interdisciplinares}

Foram propostas avaliações interdisciplinares no processo de construção do módulo de Saúde Mental, sendo que algumas avaliações foram realizadas separadamente pelas professoras de Enfermagem e Psicologia, tais como: provas 
objetivas, fichamento de medicações, atividades escritas, discussões em sala de aula.

Como atividade avaliativa, os discentes do curso Técnico em Enfermagem organizaram e realizaram a I Mostra Fotográfica: Dispositivos Existenciais de Cuidado em Saúde Mental do Instituto Federal da Bahia (IFBA), campus Eunápolis. A atividade, de caráter interdisciplinar, foi proposta pelas professoras de Enfermagem e Psicologia, juntamente com uma professora de português lotada na área de Linguagem. No intuito de aprimorar as práticas pedagógicas, é necessário que o professor articule conhecimentos de outras áreas da ciência e exercite outras formas de relacionamentos (ZERBETTO; PEREIRA, 2005).

As fotografias foram produzidas por usuários dos CAPS, com dispositivos disponibilizados pelos discentes e após esse momento foram realizadas entrevistas com os usuários, com o objetivo de conhecer o itinerário terapêutico dos usuários, bem como questões relacionadas à felicidade, à vida, aos sonhos e aos projetos. Após as entrevistas, foram realizados os ensaios fotográficos com a orientação: "fotografe aquilo que produz sensação de bem-estar e que você considera uma forma de cuidado para com sua saúde mental". Foram registrados objetos, lugares e pessoas que tinham sentido para suas vidas, objetos como bola e bicicleta, lugares como espaços públicos, praças, pontos comerciais, a casa, a igreja e o próprio CAPS e pessoas como familiares, amigo, incluindo a equipe da atenção básica.

A partir das entrevistas e fotografias, os usuários construíram textos que foram corrigidos pela professora de português e que foram expostos juntamente com as fotografias em painéis. Os grupos apresentaram seus trabalhos e no final da Mostra, os discentes disponibilizaram as fotografias para o respectivo dono. Observou-se neste momento que:

A fotografia se situa no plano do invisível, além da imagem. São emoções que não podem ser gravadas materialmente: residem em nosso ser e só a nós pertencem. São emoções que não apenas sentimos, mas que também imaginamos, sonhamos e, portanto, vemos... A impressão é de que os usuários, inebriados pelas possibilidades do aparelho fotográfico, deleitam-se em sensações que se traduzem em imagens. Imagens que impressionam, que despertam alegrias, que atropelam palavras e recuperam em nós, espectadores, a poesia; imagens que nos fazem mergulhar em um silêncio profundo... de contemplação. Esse exercício de liberdade se apresenta de forma sedutora, transformando meros atores do 
cotidiano em autores donos de suas próprias "verdades". (MENEZES; TEIXEIRA; YASUI, 2008, p. 28)

Para os usuários do CAPS, a experiência de fotografar, construir produções textuais de caráter poético e participar da Mostra Fotográfica configuraram-se em um novo despertar para a vida, um resgate e a construção de sonhos e projetos. Além disso, foi possível trabalhar questões importantes da Reforma Psiquiátrica, como o exercício e o resgate da cidadania, a valorização, o aumento da auto-estima, a ressignificação de sentidos, o estímulo ao cuidado no território, o empoderamento e a reinserção social.

Para um verdadeiro "Aprender a ser" no ambiente escolar, a arte e a poesia deveriam ter um destaque maior do que lhes é dado, buscando uma maior atenção com o desenvolvimento da imaginação e da criatividade.

\begin{abstract}
Ademais, utilizar a fotografia como meio terapêutico para pessoas com transtornos mentais é como ressignificar o olhar estrangeiro e paralisante desses sujeitos, por meio de uma espécie de bruxaria que envolve pozinhos, pitadas, luz e aparelhos, que passa a compartilhar esse fantástico poder paralisante e mortal do olhar de quem antes fora vítima do processo de exclusão social (MENEZES, TEIXEIRA, YASUI, 2008).
\end{abstract}

No processo de formação em Saúde Mental, é importante possibilitar ao discente a convivência com a pessoa que tem transtorno mental, no sentido de não o conceber como uma doença, mas como um sujeito biopsicossocial e espiritual. Assim, no processo de formação é importante salientar a relevância do "Aprender a conviver", auxiliando o discente na capacitação para evitar conflitos e levando-o a tomar consciência das semelhanças e da interdependência entre todos os seres humanos do planeta, através da experiência e do prazer do esforço comum, respeitando a diferenças culturais e espirituais de cada usuário.

Além da Mostra Fotográfica, os discentes organizaram a Mesa-redonda intitulada "Suicídio: quebrando tabus". No processo de organização, a turma do $4^{\circ}$ módulo do curso técnico de enfermagem, ficou responsável pelo apoio logístico do encontro e participou das discussões teóricas durante a realização do evento. Organizar um evento no processo formativo configura-se em uma oportunidade de "Aprender a conviver", já que todos os envolvidos precisam trabalhar juntos em um contexto igualitário, no intuito de alcançar objetivos e projetos comuns, podendo a 
partir desta experiência, levá-los ao fortalecimento dos laços de amizade (DELORS, 2003).

A mesa-redonda foi uma atividade organizada e implementada pelos discentes do quarto módulo do curso Técnico em Enfermagem, juntamente com a Comissão de prevenção ao uso abusivo de drogas do IFBA/campus Eunápolis. O encontro teve o objetivo de discutir sobre o suicídio numa perspectiva interdisciplinar a partir de diversos aspectos: epidemiológicos, sociológicos, religiosos, filosóficos, psicológicos, psiquiátricos e de saúde pública.

Importante salientar que o processo de formação pode acontecer em contextos educacionais diferenciados, assim, foi possível discutir o conteúdo teórico do módulo em um ambiente diferente da sala de aula, com outros atores sociais envolvidos. Nessa perspectiva, o processo de "Aprender a conhecer", no processo formativo, deve fornecer ao discente, instrumentos, conceitos e referências capazes de levá-lo a refletir sobre o processo de trabalho.

A mesa-redonda teve a participação de estudantes, servidores do IFBA, profissionais da rede de Saúde Mental e pessoas com transtornos mentais. Possibilitar a participação dos usuários dos CAPS na mesa-redonda, em um ambiente acadêmico, consistiu uma experiência promotora da redução de estigmas e preconceitos relacionados à "loucura" e ao usuário de drogas a partir da convivência destes com outros atores sociais em diferentes espaços. Como uma diretriz da Reforma Psiquiátrica, a reabilitação psicossocial destina-se a aumentar as habilidades da pessoa para a vida social, reduzindo os danos da experiência do transtorno mental. Assim, a separação entre o sujeito e o contexto social, promovida pela psiquiatria tradicional, é superada pelo conceito de reabilitação psicossocial, a partir do envolvimento não só de profissionais, mas de toda a comunidade, tornando-se um exercício de cidadania a partir da plena contratualidade nos três cenários: habitat, rede social e trabalho com valor social (SARACENO, 1996).

Tal fato contribuiu significativamente no processo formativo dos discentes do curso Técnico em Enfermagem, tanto no desenvolvimento de habilidades relacionadas à convivência entre eles, bem como à convivência com pessoas com transtornos mentais, preparando-os para melhor para lidar com esse público específico. Nesse sentido, a proposta foi condizente com as diretrizes da Reforma Psiquiátrica, ao se concretizar numa ação de reinserção social, resgate da autonomia, respeito à diversidade e às diferenças e exercício da cidadania, a partir 
da possibilidade desse público específico ocupar um espaço da cidade de forma livre e autônoma.

\subsection{Projeto interdisciplinar}

Os serviços de Saúde Mental são formados por equipes interdisciplinares e é importante que o técnico em Enfermagem, enquanto membro dessa equipe, reconheça os transtornos mentais como graves problemas de saúde pública. Neste contexto, o discente técnico em Enfermagem, ao desenvolver o projeto interdisciplinar em Saúde Mental, tem a oportunidade de atuar com mais autonomia no seu próprio processo formativo.

A construção do projeto ocorreu de forma coletiva. A partir das discussões teóricas realizadas em sala de aula e do estágio supervisionado, o grupo se reuniu com as professoras orientadoras (a de Enfermagem e de Psicologia), os usuários e os profissionais do CAPS II, para juntos decidirem como seria a intervenção a partir das necessidades dos usuários do serviço. Os três eixos teóricos que nortearam as práticas foram: território em saúde, reinserção social e cidadania.

O CAPS II acolhe, especificamente, adultos que possuem transtornos mentais severos e/ou persistentes e consiste em um serviço substitutivo ao hospital psiquiátrico de atendimento territorial. Refletindo sobre a reforma psiquiátrica as novas experiências de assistência consideram o ambiente em que o sujeito está inserido, abrangendo práticas comunitárias de reabilitação, desenvolvendo habilidades e acompanhando projetos pessoais (SILVA; PINHO, 2015).

No processo ensino/aprendizagem, a relação docente/discente deverá fornecer ao formando forças e referências intelectuais que lhes permitam compreender o mundo e comportar-se nele como atores responsáveis e justos, conferindo-lhe liberdade de pensamento, discernimento, sentimentos e imaginação para desenvolver seus talentos (DELORS, 2003).

A intervenção aconteceu em três momentos: o grupo "Dedinho de Prosa", a oficina de beleza e a ida à sorveteria. Neste sentido, foi previamente solicitado aos usuários que levassem um valor simbólico de dois reais para que cada um comprasse seu próprio sorvete, entretanto nenhum usuário levou o valor, o que indica a necessidade de trabalhar a geração de renda dentro dos serviços. 
O projeto interdisciplinar também opera no sentido do "Aprender a ser". A educação deve contribuir para o total desenvolvimento da pessoa, preparando o discente para elaborar pensamentos autônomos e críticos e para formular seu próprio juízo de valor, podendo decidir como agir em diferentes circunstâncias da vida (DELORS, 2003).

Neste sentido, o grupo responsável convidou o restante da turma para participarem da intervenção e contaram com a presença de alguns colegas. $O$ "Dedinho de Prosa" é um momento de acolhimento realizado em grupo toda segunda-feira, na qual os usuários relatam sobre o fim de semana, sendo um espaço propício para a escuta, a orientação e a construção de projetos terapêuticos. O grupo de acolhimento, às segundas-feiras, tem como finalidade escutar o usuário sobre seu final de semana, com o intuito de qualificar a relação entre a equipe e o usuário para efetivar a integralidade do atendimento ao sujeito e a produção do cuidado de forma mais humana e cidadã (BENEVIDES; PINTO; CAVALCANTE; JORGE, 2010).

O segundo momento, no período da manhã, envolveu o desenvolvimento de uma oficina de beleza, que é um espaço no qual é possível trabalhar questões referentes à higiene corporal e autoestima. Os discentes organizaram e providenciaram os materiais necessários para a realização da oficina. Após esse momento, os usuários almoçaram e foram levados a pé para tomarem sorvete, onde foi possível promover um momento de lazer em um ambiente territorial diferente e prazeroso para todos os envolvidos.

Cada território é único, nesse sentido é preciso criar meios para desinstitucionalizar o cuidado, considerando-se o contexto da vida quotidiana do sujeito (SILVA; PINHO, 2015). A partir da desinstitucionalização, as novas formas de tratamento permitem a relação do sujeito com a sociedade, dando-lhe autonomia (PASSOS; AIRES, 2013). A desinstitucionalização abrange a desconstrução de hospitais psiquiátricos, bem como de seus saberes e estratégias, mediante uma assistência baseada no sofrimento psíquico do sujeito e a relação com a sociedade (JORGE; RANDEMARCK; QUEIROZ; RUIZ, 2006).

Uma das principais estratégias de cuidado em Saúde Mental é a reabilitação psicossocial que propõe formas de tratamento com foco na reinserção social do sujeito a partir das diretrizes da reforma psiquiátrica. As estratégias de reabilitação psicossocial têm como objetivo devolver ao sujeito com transtorno mental o direito 
de ser único, a subjetividade, o respeito, promovendo assim qualidade de vida com acesso ao trabalho, ao lazer e ao convívio familiar (BEZERRA; DIMENSTEN, 2009). Dessa forma, torna-se possível o exercício da cidadania.

A intervenção foi cheia de significados e ressignificações a partir da possibilidade do encontro entre pessoas, muito mais do que um encontro entre profissionais e pacientes, promovendo a superação de uma enfermagem tecnicista e a conquista de um novo olhar sobre as pessoas com transtornos mentais. Assim, é necessário que a formação do Técnico em Enfermagem no campo da Saúde Mental seja baseada na superação do modelo asilar, no intuito de garantir de forma mais efetiva o exercício da cidadania das pessoas com transtornos mentais de forma livre e autônoma.

\subsection{Visita técnica}

Como atividade complementar de ensino, foi realizada uma visita técnica aos CAPS de Porto Seguro. A visita técnica consiste em um recurso metodológico de ensino de grande potencial para a educação profissional, oportunizando o encontro do discente com o universo profissional, proporcionando uma formação mais ampliada no processo ensino-aprendizagem (SOUZA; FERREIRA; SILVA; CHAVES; SILVA, 2012).

$\mathrm{Na}$ visita, os discentes foram direcionados, pelas docentes, a proporem uma dinâmica de apresentação e quebra-gelo. Foram formadas duplas envolvendo estudantes, professores, usuários e familiares. Cada dupla passava um tempo conversando, para se conhecerem melhor, após esse momento, cada dupla levantava e um apresentava o outro ao restante do grupo. Esta técnica de atividade grupal teve como objetivo conhecer os participantes, além de exercitar a escuta no processo de comunicação interpessoal, já que para apresentar o outro, cada um deveria ouvir atentamente. Após a visita ao CAPS II, os discentes puderam conhecer os outros CAPS.

O processo da Reforma Psiquiátrica tem reorientado o modelo de atenção em saúde mental, possibilitando à enfermagem um campo de possibilidades, no que se refere às práticas relacionais e com foco no sujeito. Nesse contexto, a escuta e o diálogo são habilidades inerentes ao ser humanos, configurando-se em ferramentas 
essenciais para a integralidade do cuidado (MAYNART; ALBUQUERQUE; BRÊDA; JORGE, 2014).

$\mathrm{Na}$ atividade em grupo proposta, o discente tem a oportunidade de conhecer novos sujeitos, novas experiências, novas histórias e novas formas de saber-fazer no campo profissional através do diálogo e da escuta terapêutica. No contexto da Reforma Psiquiátrica, a escuta qualificada configura-se em uma tecnologia leve do cuidado, caracterizada pelo diálogo, vínculo e acolhimento. Através dela é possível compreender o sofrimento mental, valorizando suas experiências e atentando para suas necessidades (MAYNART; ALBUQUERQUE; BRÊDA; JORGE, 2014). Quem escuta deve estar comprometido totalmente com a interação, ser sincero, autêntico e congruente, interessar-se pelo outro, estar disposto e motivado para escutar, ser empático, compreender as questões culturais, fazer-se presente por meio do silêncio, reservar tempo para escutar, manter a privacidade sem interrupções e preparar o ambiente para a escuta (SOUZA; PEREIRA; KANTORSKI, 2003).

Além da escuta, os discentes puderam conduzir uma experiência grupal, estimulando a autonomia no processo formativo. O grupo é um aspecto relevante da atenção psicossocial. Nos CAPS, o trabalho em grupo potencializa trocas dialógicas, possibilita o compartilhamento de experiência, melhora a adaptação ao modo de vida pessoal e social, estimula a convivência e a expressão de opiniões e escolhas. O grupo pode ter vários objetivos, eles podem trabalhar atividades motoras, sociais e autoexpressivas, ampliando habilidades, a autonomia e a criatividade dos sujeitos (BENEVIDES; PINTO; MENDONÇA; JORGE, 2010). Na atividade proposta e implementada, pode-se trabalhar também o respeito à diversidade e à singularidade.

Ao "Aprender a ser", há um despertar para a imaginação e criatividade, objetivando a realização completa do homem em toda sua riqueza e complexidade de expressões e compromissos, ou seja, como sujeito, membro de uma família de uma coletividade, cidadão produtor e inventor de técnicas e criador de sonhos (DELORS, 2003). Ainda para o autor, para a experiência profissional, a educação é um meio para essa realização que é, ao mesmo tempo, individualizada e construída socialmente.

No contexto da educação profissional o objetivo é qualificar, requalificar e reprofissionalizar trabalhadores, a partir do desenvolvimento de aptidões para a vida produtiva. Nesse contexto, as visitas técnicas são realizadas no intuito de complementar os conhecimentos técnicos dos discentes a partir da análise, 
avaliação, observação e relação teórico-prática (SOUZA; FERREIRA; SILVA; CHAVES; SILVA, 2012).

\section{CONSIDERAÇÕES FINAIS}

No processo formativo do Técnico em Enfermagem é necessário um novo olhar para o trabalho em Saúde Mental, a partir da superação de uma formação puramente fundamentada no domínio técnico para um processo capaz de possibilitar ao discente a compreensão e a capacidade de intervir na realidade social.

Assim, a relação entre 0 docente e o discente precisa possibilitar a construção de um novo saber-fazer em Saúde Mental, pensada a partir das diretrizes da Reforma Psiquiátrica. Neste sentido, as práticas pedagógicas devem ser capazes de superar o caráter punitivo, vigilante, controlador e disciplinador que acompanhou as atividades da Enfermagem Psiquiátrica ao longo da história da psiquiatria tradicional.

Embora os pilares da educação tenham sido apresentados separadamente, isso se configurou apenas numa tentativa didática de expor as experiências vividas, entretanto, as quatro vias do saber constituem na verdade apenas uma, já que existem entre elas vários pontos de contato, relacionamento e permuta.

O trabalho interdisciplinar é sem dúvidas o agente precursor da promoção da saúde, uma vez que a troca de saberes e experiências cooperam na melhora da assistência prestada. Sendo assim, a razão do trabalho da Enfermagem nesse novo modelo é o cuidado terapêutico, objetivando uma assistência segura, integral e de qualidade. Desta maneira, o técnico em Enfermagem deve ser empático, autêntico e com capacidade de acolher, como também saber ouvir, principalmente usuários dos serviços de saúde mental.

Como integrante da equipe multiprofissional, o técnico em enfermagem que atua na Saúde Mental deverá desenvolver habilidade de escuta para a construção do cuidado com os usuários. Neste sentido, o processo formativo desse sujeito deve oportunizar ao discente o encontro com o usuário e o familiar, compreendendo o momento da escuta como essencial para a prática profissional, embora não seja uma tarefa fácil. 


\section{REFERÊNCIAS}

BELMONTE, P.R. A reforma psiquiátrica e os novos desafios da formação de recursos humanos. ESCOLA POLITÉCNICA DE SAÚDE JOAQUIM VENÂNCIO. In: Formação de pessoal de nível médio para a saúde: desafios e perspectivas. Rio de Janeiro: editora Fiocruz, p. 224, 1996.

BENEVIDES, D.S.; PINTO, A.G.A.; MENDONÇA. C.C.; JORGE, M.S.B. Cuidado em saúde mental por meio de grupos terapêuticos de um hospital-dia: perspectivas dos trabalhadores de saúde. Interface (Botucatu), vol. 14, n. 32, p. 127-138, 2010.

BEZERRA, C.G.; DIMENSTEIN, M. Acompanhamento terapêutico na proposta de altaassistida implementada em hospital psiquiátrico: relato de uma experiência. Psicol. Clin, vol. 21, n. 1, p. 15-32, 2009.

BRASIL. Ministério da Saúde. Secretaria de Atenção à Saúde. Departamento de Ações Programáticas Estratégicas. Saúde mental no SUS: os centros de atenção psicossocial. Brasília [Internet] 2004 (acesso 24 agosto 2014). Disponível: https://www.nescon.medicina.ufmg.br/biblioteca/imagem/1212.pdf.

BRASIL. Ministério da Saúde. Secretaria de Atenção à Saúde. Coordenação Geral de Saúde Mental. Reforma psiquiátrica e política de saúde mental no Brasil. Documento apresentado à Conferência Regional de Reforma dos Serviços de Saúde Mental: 15 anos depois de Caracas. OPAS. Brasília. [Internet] 2005 (acesso 23 agosto 2014). Disponível: http://bvsms.saude.gov.br/bvs/publicacoes/Relatorio15_anos_Caracas.pdf.

BRASIL. Ministério da Saúde. Secretaria de Atenção à Saúde. Departamento de Atenção Especializada e Temática. Centros de Atenção Psicossocial e Unidades de Acolhimento como lugares da atenção psicossocial nos territórios: orientações para elaboração de projetos de construção, reforma e ampliação de CAPS e de UA. Brasília, 2015.

DELORS, J. Educação: um tesouro a descobrir. $2^{a}$ edição. São Paulo: Cortez Brasília, DF: MEC/UNESCO, 2003.

FERNANDES, J.D.; SADIGURKY, D.; SILVA, R.M.O.; AMORIM, A.B.; TEIXEIRA, G.A.S.; ARAÚJO, M.C.F. Ensino da enfermagem psiquiátrica/saúde mental: sua interface com a Reforma Psiquiátrica e diretrizes curriculares nacionais. Revista da Escola de Enfermagem, vol. 43, n. 4, p. 962-968, 2009.

FREIRE, P. Pedagogia do Oprimido. 45 ed. São Paulo: Paz e Terra, 2007.

JORGE. M. S. B.; RANDERMACK. N. F. R.; QUEIROZ. M. V. O.; RUIZ, E.M. Reabilitação Psicossocial: visão da equipe de Saúde Mental, RevBrasEnferm, v. 59. n. 6, p. 734739, 2006.

JORGE, M. S. B.; PINTO, D.M.; QUINDERÉ, P.H.D.; PINTO, A.G.A.; SOUSA, F.S.P.; CAVALCANTE, C.M. Promoção da Saúde Mental - Tecnologias do Cuidado: vínculo, acolhimento, co-responsabilização e autonomia. Ciência \& Saúde Coletiva, vol. 16, n. 7, p. 3051-3060, 2011.

LACCHINI, A.J.B.; RIBEIRO, D.B.; SOCCOL, K.L.S.; TERRA, M.G.; SILVA, R.M. A enfermagem e a saúde mental após a reforma psiquiátrica. Revista Contexto $e$ Saúde, vol. 11, n. 20, p. 565-568, 2011. 
LIPPIT, R; WATSON, J.; WESTLEY, B. The dynamics of planned change. New York, Harcourt, Brace\& World, 1958.

MACIEL, S.C.; MACIEL, C.M.C.; BARROS, D.R.; SÁ, R.C.N.; CAMINO. L.F. Exclusão social do doente mental: discursos e representações no contexto da reforma psiquiátrica. Psuci-USF, v. 13, n. 1, p. 115-124, 2008.

MAYNART, W.H.C.; ALBUQUERQUE, M.C.S.; BRÊDA, M.Z.; JORGE, J.S. A escuta qualificada e o acolhimento na atenção psicossocial. Acta Paul Enferm, vol 27, n. 4, p. 300-3, 2014.

MENEZES, M.P.; TEIXEIRA, I.; YASUI, S. O olhar fotográfico como proposta de cuidado em Saúde Mental. Arquivos Brasileiros de Psicologia, vol. 60, n. 3, p. 24-25, 2008.

MORENO, V.; SAEKI, T. Refletindo sobre a cidadania nos serviços de Saúde Mental, $\mathbf{R}$. gaúcha Enferm., Porto Alegre, v.19, n.2, p.91-94, 1998.

PASSOS. F. P.; AIRES. S. Reinserção social de portadores de sofrimento psíquico: o olhar de usuários de um Centro de Atenção Psicossocial, Physis Revista de Saúde Coletiva, v. 23, n. 1, p. 13-31, 2013.

PINTO, M.B. Ensino de enfermagem em saúde mental para formação de técnicos na perspectiva da reforma psiquiátrica. Universidade Federal da Paraíba. Programa de Pós-Graduação em Enfermagem. João Pessoa, p. 105, 2005.

PONTES, A.C.; LEITÃO, I.M.T.A.; RAMOS, I.C. Comunicação terapêutica em Enfermagem: instrumento essencial do cuidado. Revista Brasileira de Enfermagem, vol. 1, 61, n. 3, p. 312-8, 2008.

REINALDO, A. M. S.; ROCHA, R. M. Visita domiciliar de Enfermagem em Saúde Mental: idéias para hoje e amanhã. Revista Eletrônica de Enfermagem. vol. 4, n 2, p. $36-$ 41, 2002.

SAVIANI, D. Escola e Democracia. 36. ed. Campinas: Autores Associados, 2003.

SARACENO, B. Reabilitação Psicossocial: Uma estratégia para a Passagem do Milênio. In: PITTA, A. (org.). São Paulo: Hucitec, 1996. p.13-18.

SILVA, A.B.; PINHO, L.B. Território e saúde mental: contribuições conceituais da geografia para o campo psicossocial. Revenferm UERJ, Rio de Janeiro, vol. 23, n. 3, p. 420-4, 2015.

SOUZA, R.C.; PEREIRA, M.A.; KANTORSKI, L.P. Escuta terapêutica: instrumento essencial do cuidado em enfermagem. R Enferm UERJ, vol. 11, p. 92-7, 2003.

SOUZA, C.F.; FERREIRA, A.M.G.; SILVA, C.; CHAVES, F.F.; SILVA, P.H.G. O papel da visita técnica na educação profissional: estudo de caso no Campus Araguatins do Instituto Federal de Tocantins. VII Congresso Norte Nordeste de Pesquisa e Inovação, p.2, 2012.

TENÓRIO, F. A reforma psiquiátrica brasileira, da década de 1980 aos dias atuais: história e conceitos. História, Ciências, Saúde - Manguinhos, vol. 9, n. 1, p. 25-59, 2002. 
ZERBETTO, S.R.; PEREIRA, M.A.O. O trabalho do profissional de nível médio de enfermagem nos novos dispositivos de atenção em saúde mental. Rev. Latino-am Enfermagem, vol. 13, n. 1, p. 112-117, 2005) 